\title{
The Formation and Germination of Microcysts in Myxococcus xanthus
}

\author{
By M. DWORKIN AND H. VOELZ \\ Department of Microbiology, Indiana University Medical Center \\ Indianapolis, Indiana, U.S.A.
}

(Received 15 July 1961)

\begin{abstract}
SUMMARY
An investigation has been made of the sequence of morphological events involved in the processes of microcyst formation and germination in the fruiting myxobacterium Myxococcus xanthus. By using time-lapse photomicrographs and phase-contrast microscopy of living cells, microcyst formation is shown to involve a shortening and thickening of the entire vegetative cell with a subsequent increase of refractility. Germination is preceded by the casting off of a sheath followed by the gradual elongation and loss of refractility of the cell. Vegetative rods will readily form spheroplasts when exposed to a variety of conditions including sulphydryl compounds. The necessity for distinguishing between spheroplasts and microcysts is pointed out.
\end{abstract}

\section{INTRODUCTION}

During the life cycle of the fruiting myxobacterium Myxococcus xanthus, vegetative rods are converted to round refractile bodies called microcysts. These microcysts may then germinate to form the vegetative rods. Thaxter (1897) and KlienebergerNobel (1947), with Myxococcus, and Hutchinson \& Clayton (1919), with Sporocytophaga, described microcyst formation as involving a shortening and thickening of the entire vegetative cell, culminating in a round refractile body. While the subsequent literature is in essential agreement with these observations, a preliminary report (Dworkin \& Voelz, 1961) described spheroplast (' . . a globular form in which cell wall structure has been modified... rather than totally removed. . .'; McQuillan, 1960) formation by $M$. xanthus and implied that care must be exercised to distinguish spheroplasts from microcysts. Descriptions of the germination process have not always agreed. Various accounts have invoked the formation of germ tubes (Thaxter, 1897; Beebe, 1941; Loebeck \& Ordal, 1957), simple elongation (Quehl, 1906; Klieneberger-Nobel, 1947) and elongation preceded by the casting off of a mucoid sheath (Krzemieniewska, 1930; Stanier, 1942; Grace, 1951). As a prelude to a physiological investigation of these processes, we felt that an unequivocal demonstration of the morphological sequence of events in microcyst formation and germination would be invaluable. Accordingly, this communication is concerned with the processes of spheroplast formation, microcyst formation and microcyst germination in $\boldsymbol{M}$. xanthus. 


\section{METHODS}

Two strains of Myxococcus xanthus, designated FB and Mc, were used for this study. While both MC and FB can form microcysts, only FB is capable of producing mature fruiting bodies. Strain MC was derived from FB which was, in turn, obtained from the stock culture collection of the Bacteriology Department of the University of California in Berkeley. Both of these strains are dispersed-growing variants and can be cultured as vegetative organisms on a medium containing Casitone (Difco), $2 \%(\mathrm{w} / \mathrm{v}) ; \mathrm{MgSO}_{4}, 0.1 \%(\mathrm{w} / \mathrm{v}) ; \mathrm{K}_{2} \mathrm{HPO}_{4}-\mathrm{KH}_{2} \mathrm{PO}_{4}$ buffer $(0.01 \mathrm{M}, \mathrm{pH} 7 \cdot 2)$; this medium is referred to as $\mathrm{CT}$. Large numbers of vegetative organisms could be obtained in $24 \mathrm{hr}$. by incubating $30 \mathrm{ml}$. of inoculated CT medium in a $250 \mathrm{ml}$. Erlenmeyer flask with shaking, at $28^{\circ}$. On an agar medium of the same composition the two strains formed vegetative colonies with a typical myxobacterial edge. For microcyst formation the organisms were cultivated on a medium prepared by autoclaving a suspension of Escherichia coli (about $5 \times 10^{8}$ bacteria $/ \mathrm{ml}$.) and agar $(2 \%, \mathrm{w} / \mathrm{v})$ for $1.5 \mathrm{hr}$. This medium is referred to as CA.

For spheroplast formation, veretative organisms were grown with shaking in CT medium for $18 \mathrm{hr}$. The age of the organisms was not critical. The organisms were collected by centrifugation, resuspended in distilled water to their original volume, and freshly prepared cysteine (plI 7.2) added to a final concentration of $0 \cdot 1 \mathrm{M}$. The suspension was gently agitated for $1.5 \mathrm{hr}$., at which time a sample was removed and a wet mount slide prepared. The series of photographs (Plate 1) begins at this point.

For microscopical observation organisms were cultured either in a Sykes \& Moore tissue culture chamber (Sykes \& Moore, 1959) or on a modified hanging drop slide. The underside of a no. 1 coverslip was coated with a thin layer of the appropriate agar medium (CT for germination; CA for microcyst formation). The agar was inoculated with a small drop of a suspension of organisms and the coverslip sealed with paraffin to a slide. Observations were made with a phase contrast microscope and photomicrographs taken with a Polaroid Land camera adapted to

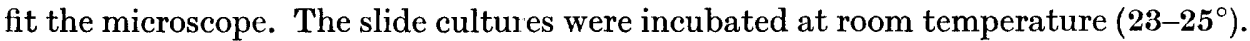

Electron micrographs of germinating microcysts were prepared as follows. CT agar was overlayed with a parlodic n membrane. The microcysts were deposited on the surface of the membrane and after 5-12 hr. incubation the membrane was floated off the agar. Grids were then prepared in the conventional manner, shadowed with palladium and observed with an RCA electron microscope.

\section{RESULTS}

\section{Spheroplast formation}

Myxococcus xanthus can be provoked to form spheroplasts by a variety of conditions, e.g. 0.5 M-sucrose (Mason \& Powelson, 1958), 0.1 M-glutathione, 0.1 M-cysteine, $0 \cdot 1 \mathrm{M}-\beta$-mercaptoethanol or by anaerobiosis. Figures $1-8$ illustrate the process of spheroplast formation in MC strain organisms exposed to cysteine. The morphological sequence of events is similar to that observed in spheroplast formation by Proteus (Liebermeister \& Kellenberger, 1956). It is of interest to note that after $6 \mathrm{hr}$. in the presence of the cysteine, the cells have acquired the refractility characteristic of microcysts. At this time, the spheroplasts may be centrifuged and resus- 
pended in distilled water without undergoing lysis. Whatever the refractility or osmotic stability of these bodies may be, we feel that any set of parameters for determining whether or not a round body is a microcyst must include the ability to germinate. By direct observation under conditions suitable for microcyst germination we have never been able to demonstrate that these bodies, or similar bodies prepared by exposing vegetative cells to the sporulation medium of Adye \& Powelson (1961), are capable of germination.

\section{Microcyst formation}

As pointed out by Thaxter (1897) the difficulty in observing microcyst formation in Myxococcus has been that the formation of the microcyst is intimately associated with the construction of the fruiting body. Since the Mc variant of Myxococcus xanthus is able to form microcysts in the absence of a fruiting body (i.e. aggregation of vegetative cells is not a prerequisite for microcyst formation) we were able to circumvent this difficulty. Microcyst formation in both the $\mathrm{MC}$ and $\mathrm{FB}$ variants is strictly controlled by the nutritional milieu (Dworkin, unpublished observation). We were, accordingly, able to obtain microcyst formation at will by incubating the cells on CA medium. When vegetative cells of strain MC were incubated on a CA medium slide culture, the results illustrated in Pl. 1, fig. 9-14, were obtained. While Figs. 9 through 14 are of the same field, the vegetative cells in Figs. 9 and 10 are gliding across the agar and one is, therefore, not viewing the same cells in subsequent frames. In Fig. 11, however, most of the cells have stopped migrating and one can follow the development of selected cells. After $48 \mathrm{hr}$. (Fig. 11) the vegetative cells become shorter and thicker, during which process they lose their motility. At $72 \mathrm{hr}$. (Fig. 12) the cells have begun to acquire refractility and by $96 \mathrm{hr}$. most of the cells have completed the process of microcyst formation (Fig. 13). To determine whether these cells were indeed capable of germination, a drop of CT medium was added to the area. The cells were observed to germinate (Fig. 14). The oval cells are not in the process of germination but are vegetative cells which have not completed the process of microcyst formation.

\section{Microcyst germination}

Microcysts germinated readily when placed on the solid CT medium. Time-lapse photomicrographs of the germination process of $\mathrm{FB}$ microcysts on $\mathrm{CT}$ slide culture indicate the following sequence of events (Plate 2). There is a lag period of about $5 \mathrm{hr}$. during which no observable changes take place. Suddenly, events begin to move rapidly. The microcyst begins to lose its refractility and gradually lengthens until it has assumed a rod shape. This process is usually completed in 3-5 hr. During this process, it appears as if a sheath of some sort is discarded (Pl. 2, fig. 17-20). There is no evidence of any sort of germ tube formation. Electron micrographs of germinating microcysts are consistent with this view. Plate 2, fig. 21, shows a microcyst which has not begun to germinate. In Fig. 22 the microcyst has begun to germinate, the cast off sheath is evident, and the cell has become clearly oval shaped. Fig. 23 shows the completed vegetative cell with its discarded sheath. 


\section{DISCUSSION}

It is clear, at least under our particular conditions, that Myxococcus xanthus forms microcysts by a process of shortening and thickening of the vegetative rods with a subsequent increase in refractility of the cells. This is consistent with the observations of Thaxter (1897) on Myxococcus rubescens, Hutchinson \& Clayton (1919) and Krzemieniewska (1930) on Sporocytophaga, and others. Microcysts thus formed differ from the refractile spheroplasts not only in the sequence of morphological events leading to their formation but also in their ability to germinate.

Germination of microcysts is preceded by the casting off of a sheath, which may be cell wall material or slime. The cell then elongates to form the vegetative rod. Some of the references to microcyst germination have invoked the formation of a germ tube (Thaxter, 1897; Beebe, 1941; Loebeck \& Ordal, 1957). It is possible that these investigators were observing various stages in spheroplast formation. It is evident from Plate 1 that some of the torms intermediate in spheroplast formation could be mistaken for germinating microcysts. These spheroplasts appear quite frequently in old cultures. In following a sequence of morphological events, it is important that one should observe the same cells throughout the sequence. The practice of removing samples from a culture at intervals and piecing together a life cycle or series of changes can be misleading.

The conversion of vegetative cells to spheroplasts when exposed to anaerobiosis or sulphydryl compounds may provide a hint as to the nature of the processes of microcyst formation and germination. Sulphydryl-activated (and oxygen-inhibited) proteolytic enzymes are well known (Irving, Fruton \& Bergmann, 1942), and Nickerson \& Falcone (1956) have described the enzymic reduction of disulphide bonds in the cell walls of yeast. It is conceivable that sulphydryl-activated proteolytic enzymes play a role in the alterations of the cell wall necessary for the rod to microcyst conversions. If such be the case, the nature of the environmental stimulus for this activation would be of interest. The striking dependence of microcyst formation on the nutritional milieu probably reflects an important regulatory factor. The nature of this control is currently under investigation.

This investigation was supported by a grant from the Developmental Biology Program of the National Science Foundation.

\section{REFERENCES}

Adye, J. C. \& Powelson, D. M. (1961). Microcyst of Myxococcus xanthus. Chemical composition of the wall. $J . B a c t .81,780$.

BEEBE, J. M. (1941). The morphology and cytology of Myxococcus xanthus, n.sp. J. Bact. 42, 193.

Dworkin, M. \& Voelz, H. (1961). Microcyst formation and germination in Myxococcus xanthus. Bact. Proc. p. 85.

Grace, J. B. (1951). The life cycle of Sporocytophage. J. gen. Microbiol. 5, 519.

Hutchinson, H. B. \& Clayton, J. (1919). The decomposition of cellulose by an aerobic organism (Spirochaeta cytophaga n.sp.). J. agric. Sci. 9, 143.

Irving, G. W., Fruton, J. S. \& BergmanN, M. (1942). On the proteolytic enzymes of animal tissue. IV. Differences be tween aerobic and anaerobic proteolysis. J. biol. Chem. $144,161$. 
Jourmal of General Microbiology, Vol. 28, No. 1

Plate 1
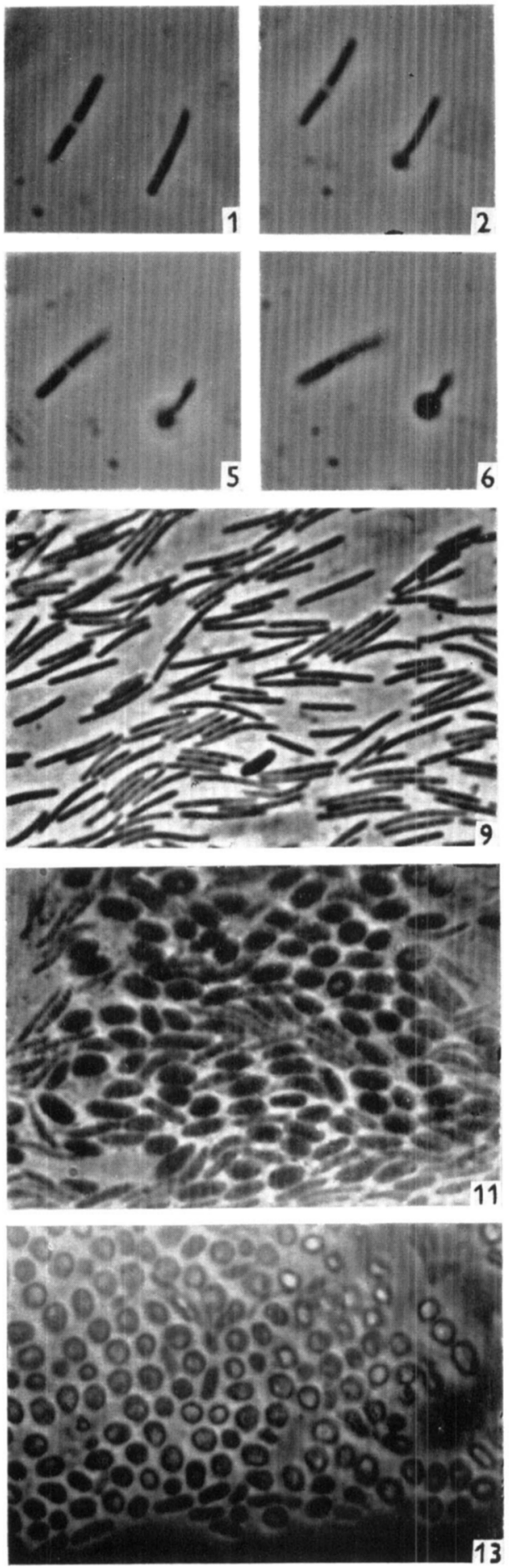

6
Time (min.)
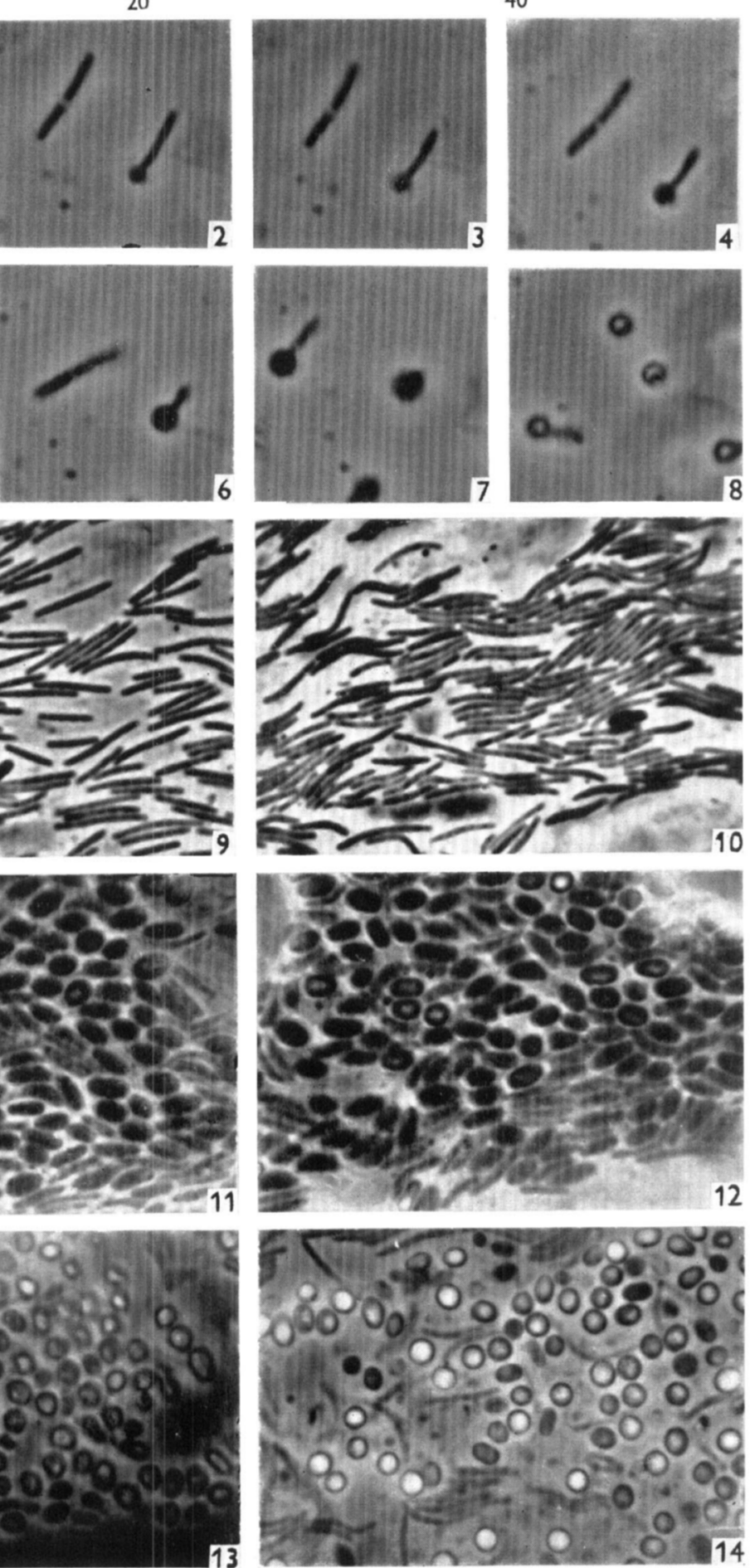

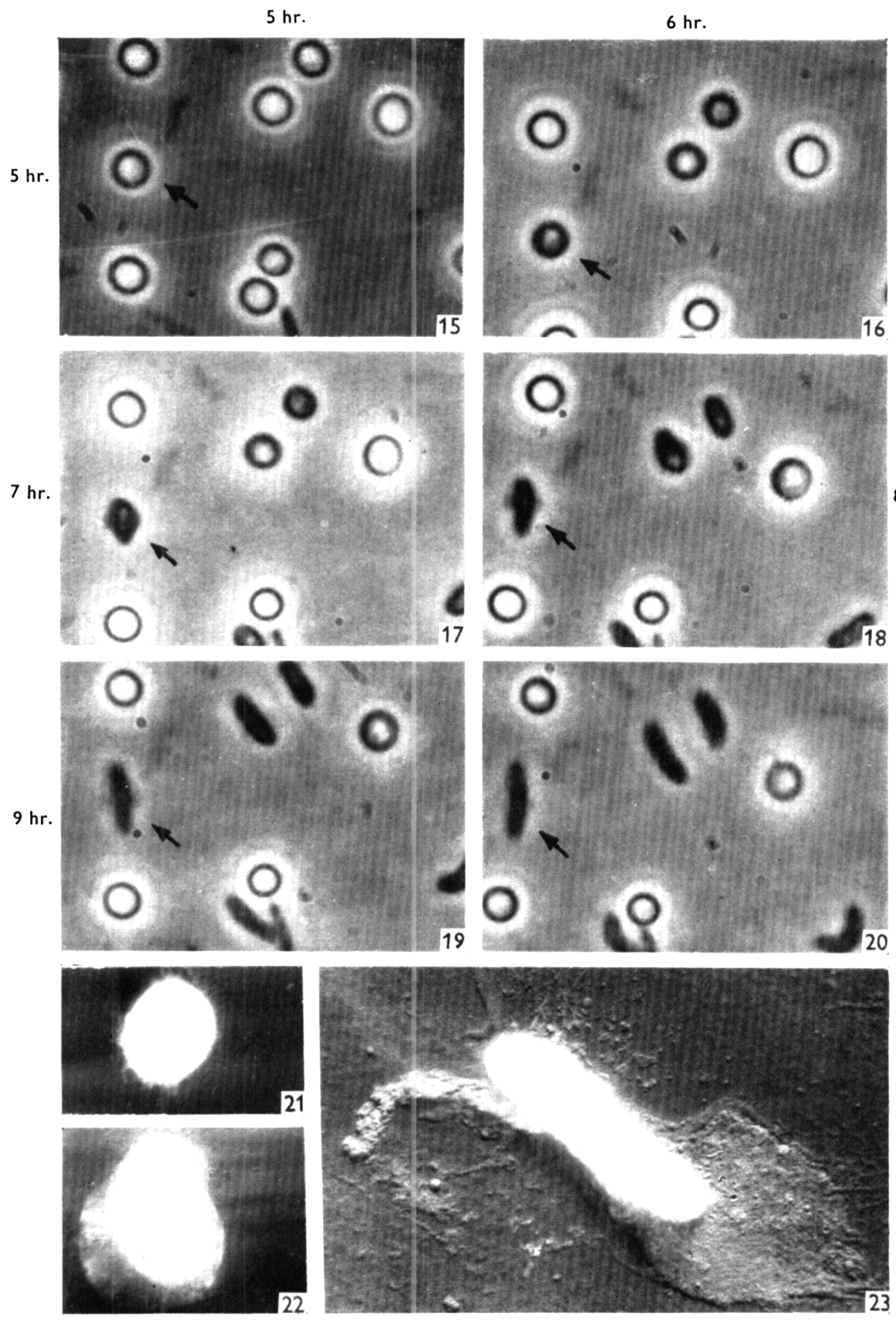

M. DWORKIN AND H. VOLILZ 
Klieneberger-Nobel, E. (1947). A cytological study of myxococci. J. gen. Microbiol. 1, 33.

Krzemieniewska, H. (1930). Le cycle évolutif de Spirochaeta cytophaga. Acta Soc. Bot. Polon. 7, 507.

Liebermeister, K. \& Kellenberger, E. (1956). Studien zur L-Form der Bakterien. I. Die Umwandlung der bazillären und die globuläre Zellform bei Proteus unter Einfluss von Penicillin. $Z$. Naturf. $11 b, 200$.

Loebeck, M. E. \& Ordal, E. J. (1957). The nuclear cycle of Myxococcus fulvis. J. gen. Microbiol. 16, 76.

Mason, D. J. \& Powelson, D. (1958). Lysis of Myxococcus xanthus. J. gen. Microbiol. $19,65$.

MCQuillan, K. (1960). 'Bacterial Protoplasts', in The Bacteria, Vol. ז: Structure, Ed. by I. C. Gunsalus \& R. Y. Stanier. New York: Academic Press, p. 258.

Nickerson, W. J. \& Falcone, G. (1956). Enzymatic reduction of disulfide bonds in cell wall protein of baker's yeast. Science, 124,318 .

Quent, A. (1906). Untersuchungen über die Myxobakterien. Zbl. Bakt. (Abt. 2), 16, 9.

Stanier, R. Y. (1942). The Cytophaga group: A contribution to the biology of the myxobacteria. Bact. Rev. 6, 143.

Sykes, J. A. \& Moore, E. B. (1959). A new chamber for tissue culture. Proc. Soc. exp. Biol., N.Y. 100, 125.

Thaхтеr, R. (1897). Contributions from the cryptogamic laboratory of Harvard University XXXIX. Further observations on the myxobacteria. Bot. Gaz. 23, 395.

\section{EXPLANATION OF PLATES}

\section{Plate 1}

Figs. 1-8. Cysteine-spheroplast formation from vegetative organisms of Myxococcus xanthus. $\times$ 1880. Fig. 1. 0 time. Fig. 2. $20 \mathrm{~min}$. Fig. $40 \mathrm{~min}$. Fig. $4.70 \mathrm{~min}$. Fig. 5. $100 \mathrm{~min}$. Fig. 6. $160 \mathrm{~min}$. Fig. 7. $250 \mathrm{~min}$. Fig. $8.300 \mathrm{~min}$.

Figs. 9-13. Microcyst formation in MC vegetative organisms of Myxococcus xanthus. $\times 1500$.

Fig. 9. 0 time. Fig. 10. 24 hr. Fig. 11. 48 hr. Fig. 12. 72 hr. Fig. 13. 96 hr. Fig. 14. 120 hr. with germination taking place.

\section{Plate 2}

Figs. 15-20. Germination of $\mathrm{FB}$ microcysts. $\times 3000$. Fig. 15. $5 \mathrm{hr}$. Fig. 16. $6 \mathrm{hr}$. Fig. 17. $7 \mathrm{hr}$. Fig. 18. 8 hr. Fig. 19. 9 hr. Fig. 20. $10 \mathrm{hr}$.

Figs. 21-23. Electron micrographs of stages in germination of FB microcysts. $\times 13,500$. Fig. 21 . Ungerminated microcyst. Fig. 22. Germinating microcyst. Fig. 23. Vegetative cell, newly formed from microcyst. 